\title{
Aquaporin 9 expression in the developing rat epididymis is modulated by steroid hormones
}

\author{
Núria M Pastor-Soler ${ }^{1,2}$, Jane S Fisher ${ }^{3}$, Richard Sharpe ${ }^{3}$, Eric Hill ${ }^{1}$, Alfred Van Hoek ${ }^{1,2}$, \\ Dennis Brown ${ }^{1,2}$ and Sylvie Breton ${ }^{1,2}$ \\ ${ }^{1}$ Program in Membrane Biology and Nephrology Division, Center for Systems Biology, Massachusetts General \\ Hospital, 185 Cambridge Street, Suite CPZN 8.204, Boston, Massachusetts 02114, USA, ${ }^{2}$ Harvard Medical School, \\ Boston, Massachusetts 02115, USA and ${ }^{3}$ Medical Research Council Human Reproductive Sciences Unit, The Queen's \\ Medical Research Institute, Centre for Reproductive Biology, Edinburgh EH16 4TJ, UK
}

Correspondence should be addressed to S Breton at Program in Membrane Biology and Nephrology Division, Center for Systems Biology, Massachusetts General Hospital; Email: breton.sylvie@mgh.harvard.edu

N M Pastor-Soler is now at the Renal-Electrolyte Division, Department of Medicine, University of Pittsburgh School of Medicine, Pittsburgh, Pennsylvania 15261, USA

\begin{abstract}
Fluid and solute transport across the epithelium of the male excurrent duct is important for sperm maturation and storage. Aquaporin 9 (AQP9), which allows permeation of water and neutral solutes, is abundant throughout the male reproductive tract, where it is expressed at the apical membrane of rat epididymal principal cells as early as at 1 week of age. We evaluated the effect of neonatal exposure to: 1) a GNRH antagonist (GNRHa); 2) diethylstilbestrol (DES); 3) ethinyl estradiol (EE); 4) DES plus testosterone (DES+ TE); and 5) the anti-androgen flutamide on AQP9 expression in the epididymis of peripubertal rats. Control groups received the vehicle alone. In 25-day-old rats, quantification of the mean pixel intensity of immunofluorescence-stained sections showed a significant decrease in AQP9 staining in the apical membrane of epididymal principal cells after treatments with GNRHa, DES, or flutamide, compared to controls. These results were confirmed by western blotting. While EE induced a marked decrease in AQP9 levels by western blotting, the decrease in AQP9-associated fluorescence was not significant compared to controls. DES + TE-treated rats showed levels of AQP9 protein similar to controls, indicating maintenance of AQP9 expression by testosterone treatment in the presence of DES. Our data show that expression of AQP9 in the developing rat epididymis is downregulated by neonatal DES, GNRHa, EE, and flutamide, and that the effects mediated by estrogens can be prevented by testosterone administration.
\end{abstract}

Reproduction (2010) 139 613-621

\section{Introduction}

The luminal fluid of the male excurrent duct (efferent ducts, epididymis, and vas deferens) undergoes significant changes in composition as it moves distally (Levine \& Marsh 1971, Ilio \& Hess 1994, Hinton \& Palladino 1995, Robaire \& Viger 1995, Turner 1995, Clulow et al. 1998, Robaire et al. 2006, Joseph et al. 2009). Fluid transport across the efferent duct and epididymal epithelium is required to achieve proper sperm concentration, which is in turn important for fertility (Levine \& Marsh 1971, Johnson \& Howards 1977, Wong \& Yeung 1978, Hohlbrugger \& Pfaller 1983, Turner \& Cesarini 1983, Ilio \& Hess 1994, Clulow et al. 1998, Hansen et al. 2004). In the cauda epididymidis, the activity of an $\mathrm{Na} / \mathrm{H}$ exchanger and the $\mathrm{Na} / \mathrm{K}$-ATPase has been implicated in net water reabsorption (Wong \& Yeung 1977, Bagnis et al. 2001, Leung et al. 2001, Kaunisto \& Rajaniemi 2002). In addition, fluid secretion driven by CFTR-dependent chloride secretion occurs in the distal portion of the epididymis and helps control the viscosity of the luminal content (Wong 1998).

Water channels (aquaporins, AQPs) are involved in fluid transport in a wide variety of epithelia (Brown et al. 1995, Verkman 2002, King et al. 2004). Two subgroups of mammalian AQPs have been defined: the 'aquaporins', which are highly selective for water, and the 'aquaglyceroporins', which can transport solutes in addition to water. Several AQPs are expressed throughout the male excurrent duct (Brown et al. 1993, Stevens et al. 2000, Badran \& Hermo 2002, Da Silva et al. 2006a, $2006 b$, Hermo et al. 2008). However, the most predominant AQP in the male reproductive tract is clearly AQP9, which is expressed at high levels in the apical membrane of nonciliated cells of the efferent ducts, and principal cells all along the length of the epididymis and vas deferens (Elkjaer et al. 2000, Pastor-Soler et al. 2001, Badran \& Hermo 2002, Pietrement et al. 2008). 
Interestingly, one of the solutes that can permeate through AQP9 is glycerol (Tsukaguchi et al. 1998), a spermatozoa metabolic substrate that accumulates in the lumen of the distal epididymis (Cooper \& Brooks 1981). We have shown significant AQP9-dependent glycerol permeability in the apical membrane of epididymal epithelial cells (Pietrement et al. 2008). AQP9 was, thus, identified as a major apical AQP in the epididymal epithelium, where it could provide a route via which transepithelial fluid and solute transport could occur.

In the efferent ducts of the adult male excurrent duct, reabsorption of luminal fluid is regulated by both androgens and estrogens (Wong \& Yeung 1978, Hess et al. 1997, Hess 2003, Ruz et al. 2006). We have shown that treatment of rodents and primates with diethylstilbestrol (DES) during the neonatal period strongly inhibits AQP1 expression in the efferent ducts of prepubertal animals (Fisher et al. 1998), indicating that maintaining the estrogen/androgen balance during postnatal development is crucial for the maturation of these segments.

In the epididymis, AQP9 regulation is less well documented. We have shown that AQP9 permeability is acutely regulated by luminal bradykinin (Belleannee et al. 2009). However, the role of sex hormones in regulating its expression has not been fully characterized. The promoter region of AQP9 contains a putative steroid hormone receptor-binding site (Tsukaguchi et al. 1998). In addition, sex-linked differences of AQP9 expression have previously been reported in the liver, suggesting that different hormonal profiles during and after development may play a role in the expression of this protein (Nicchia et al. 2001). We and others have previously shown that orchidectomy (Pastor-Soler et al. 2002, Oliveira et al. 2005), or treatment of adult male rats with the antiandrogen flutamide (Pastor-Soler et al. 2002), caused a significant reduction in the level of AQP9 protein expression in the adult epididymis. The downregulation of AQP9 expression in castrated animals was reversed by testosterone in the cauda epididymidis (Pastor-Soler et al. 2002) and by dihydrotestosterone in the initial segments (Oliveira et al. 2005), indicating that androgens are important for AQP9 expression in the epididymis of adult animals. Androgen and estrogen ( $\alpha$ and $\beta$ ) receptors are expressed in the epididymis during development and in adults (McKinnell et al. 2001, Zhou et al. 2002, Hess 2003). Neonatal exposure to the estrogenic compound DES significantly affects the morphology of the male excurrent duct, including efferent ducts, epididymis, and vas deferens (McKinnell et al. 2001, Williams et al.2001, Rivas et al. 2002, 2003, Goyal et al. 2003, Atanassova et al. 2005). Disturbances in the estrogen/androgen balance were proposed to be the key determinant in causing these adverse effects on male reproductive parameters. In addition, our previous study showed a marked reduction in the number of clear cells in the epididymis of prepubertal rats after neonatal exposure to
DES (Fisher et al. 2002), a finding that further supports the notion that the epididymis is also susceptible to changes in the androgen/estrogen balance.

We have shown that AQP9 begins to appear in the apical membrane of epididymal principal cells as early as 1 week of age, and that its expression continues to increase throughout the postnatal period to reach the highest levels shortly before puberty (Pastor-Soler et al. 2001). This progressive increase in principal cell AQP9 expression during the prepubertal period was also confirmed by another laboratory (Badran \& Hermo 2002). These findings suggest that initiation of AQP9 expression in the developing epididymis does not depend exclusively on the higher androgen levels that are triggered at puberty, and might require the participation of other hormones, including estrogens. The present study, therefore, assesses whether neonatal treatment with compounds known to affect the androgenic/estrogenic balance alters the expression of AQP9 in the epididymis in the peripubertal period. Understanding the effect of hormone manipulation during the neonatal period is crucial, because overexposure of young males to exogenous estrogens, including those from various environmental sources, can result in major abnormalities and reproductive dysfunction in adulthood (Atanassova et al. 1999, Goyal et al. 2003).

\section{Results}

\section{Hormonal effects on epididymal AQP9 expression}

Effect of GNRH antagonist, DES, ethinyl estradiol, and $D E S+T E$ treatments

The expression of AQP9 was assessed by immunofluorescence staining of cryostat sections of the proximal cauda epididymidis, a region that shows high AQP9 expression. Control incubations were first performed using anti-AQP9 antibodies that had been preabsorbed with the AQP9 immunizing peptide. As we have previously described, AQP9 was localized to the apical membrane of principal cells in the epididymis of adult, as well as prepubertal rat epididymis (Fig. 1). This apical staining reached maximum intensity between the third and fourth postnatal weeks. Pre-incubation of the antibody with the AQP9 peptide completely abolished principal cell apical staining at all time points, demonstrating specificity of the antibody for AQP9.

In a separate cohort of animals, a strong AQP9 staining, comparable to that seen in adult animals, was observed in the apical membrane of principal cells of control 25-day-old rats (Fig. 2A and F). GNRH antagonist (GNRHa) and DES treatments during the neonatal period induced a marked decrease in AQP9 staining intensity, leading to an almost complete disappearance of staining in some tubules (Fig. 2B and C). Ethinyl estradiol (EE) also induced a reduction in AQP9 staining, although less 

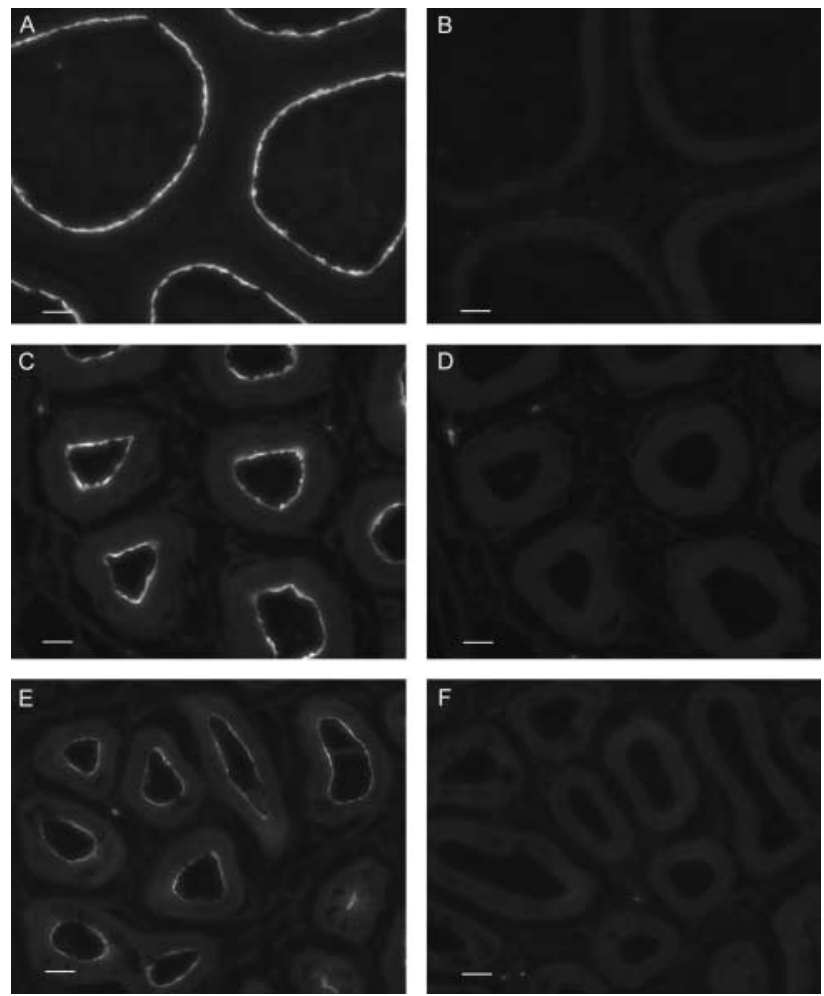

Figure 1 AQP9 immunostaining in the proximal cauda epididymidis of an adult rat (A), a 4-week-old rat (C), and a 3-week-old rat (E). A bright staining was detected in the apical membrane of principal cells at all time points. The staining reached maximal intensity, comparable to adult levels, between the third and fourth postnatal weeks. (B, D and F) Pre-incubation of the antibody with the AQP9 peptide completely abolished the staining at all time points. B, control; D, 4-week-old; F, 3-week-old epididymis. Bars $=25 \mu \mathrm{m}$.

marked than the reduction observed with GNRHa or DES (Fig. 2D and G). Animals treated with DES together with testosterone showed AQP9 levels similar to that of control animals (Fig. 2E).

The level of AQP9 expression was quantified for each treatment by digital quantitative immunofluorescence labeling. Images from immunostained sections were acquired with a digital camera using identical parameters, and the mean pixel intensity (MPI) of the apical AQP9-associated fluorescence was quantified. For each rat, the MPI was normalized relative to the average control group value. Figure 3 shows the averaged normalized MPI for each animal group. A one-way ANOVA analysis revealed a highly significant effect of treatment $(P<0.0005)$. A Tukey's post hoc test showed marked reductions in AQP9 protein expression in the GNRHa- and DES-treated groups, compared to the control group $(P<0.0005)$. The EE-treated rats showed a reduction in AQP9 MPI, although the effect was not statistically significant compared to controls $(P=0.149)$. Animals treated with both DES and testosterone (DES $+\mathrm{TE}$ ) showed significantly brighter AQP9 epididymal apical membrane staining compared to DES-treated animals $(P<0.0005)$, with $\mathrm{MPI}$ values that were slightly, but not significantly, increased compared to controls $(P=0.479)$.

\section{Effect of flutamide}

A separate cohort of rats was treated with the androgen receptor antagonist flutamide or with the vehicle during the neonatal period. Visual inspection of epididymis sections from 25 day-old rats showed a decrease in AQP9 immunofluorescence in the apical membrane of principal cells of the cauda epididymidis after flutamide treatment, compared to control (Fig. 4). This impression was confirmed by quantification of AQP9-associated MPI (Fig. 5), which revealed a significant decrease in AQP9 protein expression in the apical membrane of principal cells in the flutamide-treated group, compared to controls $(P<0.05)$.

\section{Immunoblotting (SDS-PAGE and western blotting)}

Western blots were performed using total epididymal homogenates in order to confirm the effects of the different hormonal treatment in the expression of AQP9 expression seen by immunofluorescence labeling (Fig. 6). As we have previously described, the affinitypurified AQP9 antibody detected a main band at an apparent molecular weight of $30-35 \mathrm{kDa}$, as well as additional higher molecular weight bands in total homogenates of epididymis (caput, corpus, and cauda) of control animals (Pastor-Soler et al. 2001, 2002, Pietrement et al. 2008). No AQP9 bands were detected in lanes containing the same amount of protein from total epididymal extracts of animals treated with GNRHa, DES, and EE. The DES + TE group showed a stronger signal for AQP9 compared to the DES-treated animals, indicating maintenance of AQP9 protein expression by testosterone in the presence of DES. A very faint AQP9 band was observed in flutamide-treated animals.

\section{Discussion}

Previous studies have shown that AQP9 can be detected in the developing excurrent ducts as early as 1 week postnatally, indicating that its expression does not strictly depend on the high androgen levels that are triggered during puberty. Accordingly, either the low androgen levels found in prepubertal males or other factors were proposed to be involved in AQP9 expression. The present study shows that AQP9 expression in principal cells of peripubertal rats, as quantified by immunofluorescence and visualized by western blotting, is greatly decreased following perinatal exposure to either the GNRHa, antarelix, or the estrogenic compound, DES. Exposure of neonatal rats to $\mathrm{EE}$ also decreased the level of expression of AQP9 in epididymal homogenates by 

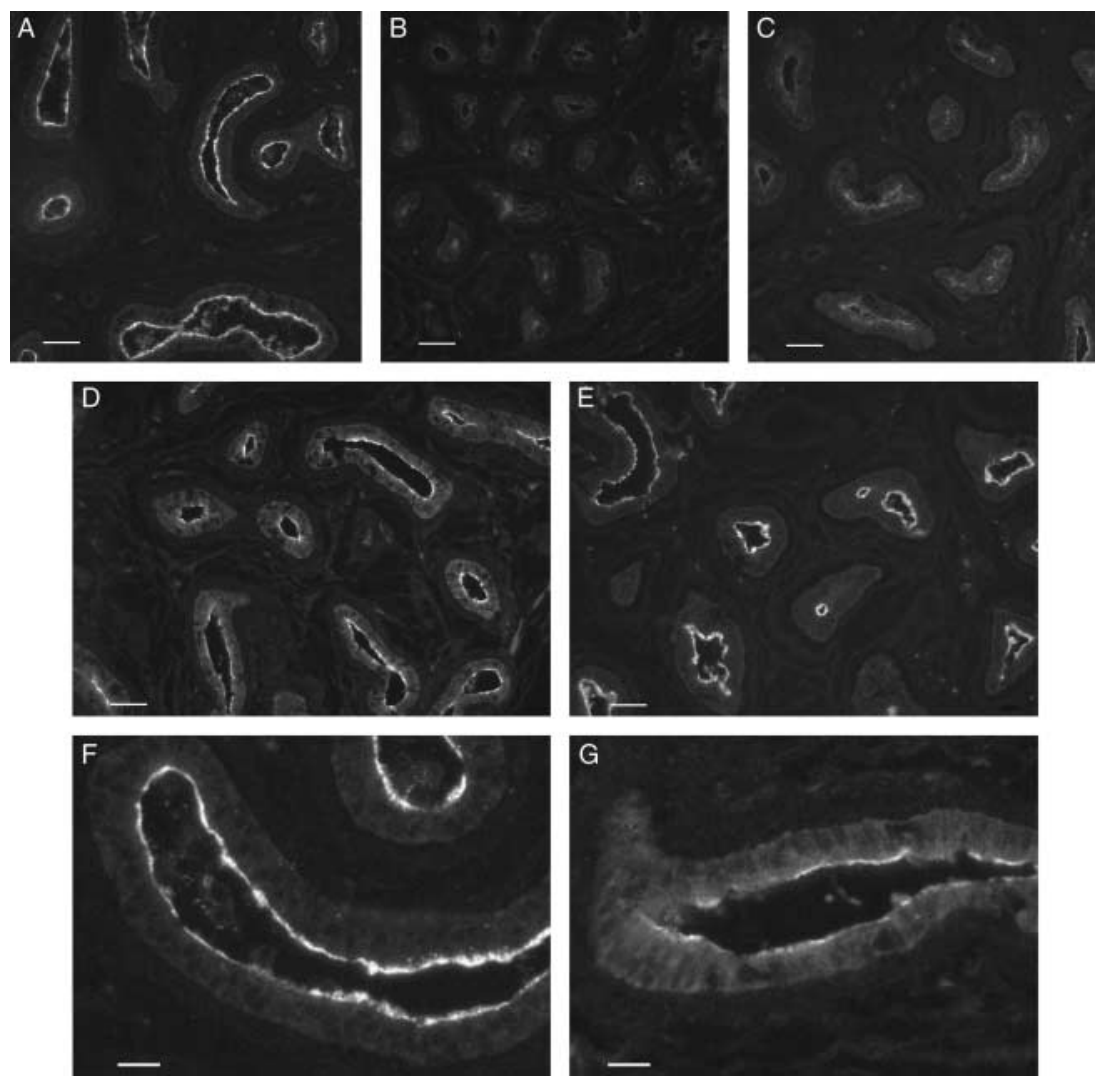

Figure 2 AQP9 immunostaining in the cauda epididymidis of 25-day-old rats after neonatal treatment with $(\mathrm{A})$ vehicle (control); (B) GNRHa; (C) DES; (D) EE; and (E) DES + TE. (F and G) Higher magnification pictures of control and EE-treated animals respectively. GNRHa and DES treatments caused a marked decrease in apical AQP9 staining. EE-treated animals showed a moderate decrease in AQP9 immunofluorescence labeling. Administration of TE maintained AQP9 expression in DES-treated rats at control levels. Digital images were acquired using identical parameters. (A-E) Bars $=40 \mu \mathrm{m}$. ( $\mathrm{F}$ and $\mathrm{G}$ ) Bars $=15 \mu \mathrm{m}$. western blot. However, the decrease that we observed by immunofluorescence staining failed to reach statistical significance in EE-treated animals, probably reflecting the different sensitivities of the two techniques. Quantification of AQP9 expression by immunofluorescence was restricted to the proximal cauda epididymidis, a region that expresses high levels of AQP9, while assessment of AQP9 expression by western blotting was performed on whole epididymis extracts. Thus, it remains possible that other epididymal regions were more strongly affected by $\mathrm{EE}$, leading to the marked reduction in AQP9 signal observed by western blotting compared to our immunofluorescence measurements of the cauda region. The same cohort of animals showed a marked reduction in testis weight and plasma testosterone levels after treatment with GNRHa, DES, and EE (Fisher et al. 2002). In addition, expression of AR was almost completely inhibited by DES, but it was not affected by GNRHa (McKinnell et al. 2001). Both $\alpha E R$ (ESR1) and $\beta E R$ (ESR2) expression remained intact following these treatments (McKinnell et al. 2001). Thus, the reduced expression of AQP9 that we observed here following DES exposure could have been attributed to either inhibition of androgen activation, increase in estrogen stimulation, or both.

Flutamide alone prevented the induction of AQP9 in neonatal rats (this study) and significantly reduced AQP9 levels in adult rats (Pastor-Soler et al. 2002) showing the androgen requirement of AQP9 expression in the epididymis. Flutamide did not affect testis weight or plasma testosterone levels in the same animals (Fisher et al. 2002), showing that it did not suppress the hypothalamo-pituitary axis, and further indicating that direct inhibition of epididymal androgen action is sufficient to inhibit AQP9 expression. In addition, when testosterone was administered together with DES, AQP9 expression was maintained at control levels. Altogether, these findings suggest that the effects elicited by DES could be solely attributed to a marked inhibition of androgen stimulation secondary to elevation of estrogen levels.

The fact that normal AQP9 expression necessitates androgen stimulation implies that, during normal postnatal development, the lower levels of circulating androgens in prepubertal male rats compared to adults are essential and sufficient to trigger the progressive expression of AQP9 that was previously observed between postnatal weeks 1 and 4 (Pastor-Soler et al. 2001, Badran \& Hermo 2002). The developmental pattern of expression of AQP9 in principal cells mimics that of V-ATPase in clear cells in the epididymis (Breton et al. 1999). The effects elicited by GNRHa, DES, EE, and flutamide on principal cell AQP9 expression also correlate with the marked decrease that we observed 


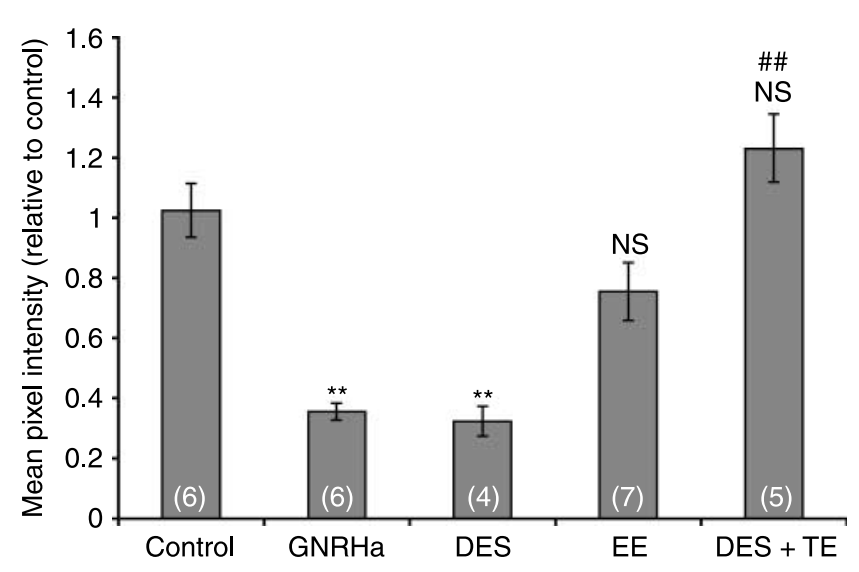

Figure 3 Quantification of AQP9-associated fluorescence staining in the cauda epididymidis of 25-day-old control and treated rats (groups represented in Fig. 1). Significant decreases in AQP9 staining intensity were induced by GNRHa and DES. EE also induced a reduction in AQP9 staining but the difference was not significant versus control. Co-administration of testosterone with DES completely restored AQP9 staining compared to DES alone, with AQP9 staining intensity comparable to control. Data are expressed relative to control, and represent the means \pm S.E.M. obtained from 4 to 7 animals per group. ${ }^{* *} P<0.0005$ versus control; ${ }^{\#} P<0.005$ versus DES; NS, not significant versus control.

in the number of V-ATPase-rich clear cells in the epididymis of the same cohort of rats (Fisher et al. 2002). These results indicate that similar factors are involved in the steroid hormone regulation of both principal cells (expressing AQP9) and clear cells (expressing V-ATPase) in the epididymis. In contrast, a previous study has shown different effects of the same
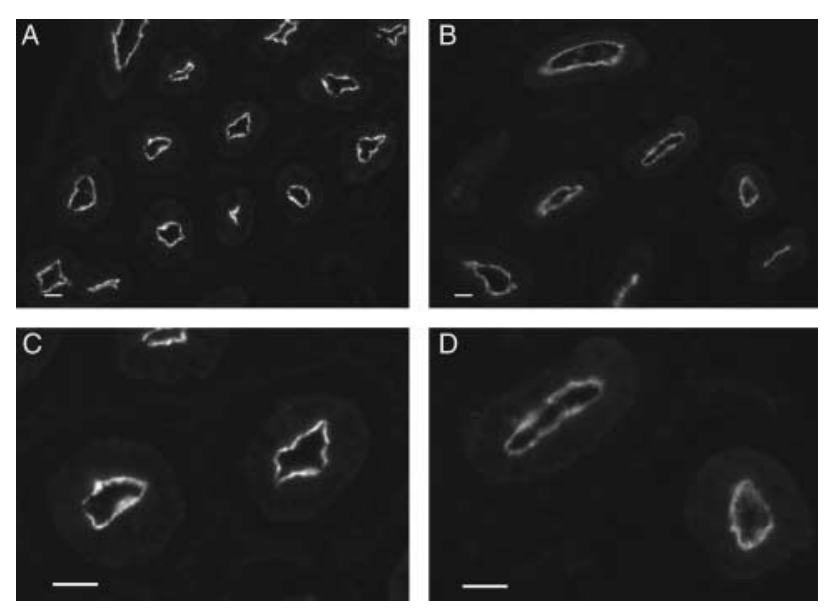

Figure 4 Downregulation of AQP9 expression in the cauda epididymidis of 25-day-old rats by the anti-androgen flutamide. Immunofluorescence for AQP9 in the cauda epididymidis from a control rat (A) and a flutamide-treated rat (B) showing a marked decrease in apical AQP9 staining in the flutamide-treated animal. Panels C and D are higher magnification representations of some of the tubules shown in $A$ and $B$ respectively. Digital images were acquired using identical parameters. Bars $=25 \mu \mathrm{m}$. treatments on the appearance of basal cells in the cauda epididymis and vas deferens (Atanassova et al. 2005). While the appearance of basal cells was inhibited by neonatal DES treatment, GNRHa or flutamide did not alter basal cell numbers. However, testosterone administration together with DES restored their number to normal levels, and it was concluded that the concomitant exposure to high estrogen and low androgen levels was essential to inhibit basal cell development (Atanassova et al. 2005). Therefore, it appears that different cell types within the same tissue might be regulated in slightly different ways by steroid hormones. Whereas suppression of the androgen response is sufficient to reduce AQP9 expression in principal cells (this study) and prevent clear cell development (Fisher et al. 2002), basal cells require both androgen and estrogen actions to develop normally (Atanassova et al. 2005). Basal cells have recently been shown to regulate adjacent principal and clear cells via crosstalk (Cheung et al. 2005, Shum et al. 2008), and their regulation by both hormones might have general implications in the overall function of the epididymal epithelium.

The present study suggests that altered expression of AQP9 in the day 25 epididymis after exposure to compounds known to affect the estrogen/androgen balance is a direct result of insufficient androgen action during neonatal development. These results are in agreement with previous studies from our laboratory and others showing that androgen replacement after castration of adult rats is sufficient to maintain AQP9 expression in the initial segment and cauda epididymis (Pastor-Soler et al. 2002, Oliveira et al. 2005), whereas estrogen replacement failed to retain AQP9 expression in the initial segment (Oliveira et al. 2005). The promoter region of AQP9 contains a putative steroid hormonebinding element (Tsukaguchi et al. 1998), and AQP9 expression in the liver shows gender differences, being higher in men than in women (Nicchia et al. 2001), further indicating that AQP9 expression is under the control of androgens. In contrast in the efferent ducts, estrogen replacement is sufficient to maintain AQP9 expression after castration (Oliveira et al. 2005, Picciarelli-Lima et al. 2006). DES administration during the neonatal period increased AQP9 protein expression in the efferent ducts, but caused a marked downregulation of AQP9 in the liver (Wellejus et al. 2008). Altogether, these results show that while AQP9 is definitely under the control of steroid hormones, the role of estrogen, androgen, or an appropriate estrogen/ androgen balance in its regulation strongly depends upon the cell type in which AQP9 is expressed. In conclusion, this study emphasizes the role of steroid hormones in the establishment and maintenance of AQP9 in the epididymis, and further illustrates the importance of monitoring environmental factors that affect hormonal balance as potential mediators of male fertility. 


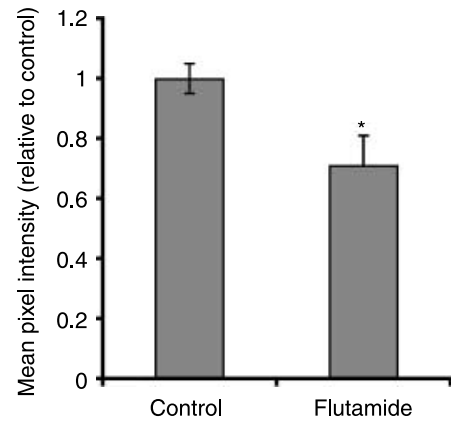

Figure 5 Quantification of AQP9-associated fluorescence staining in the cauda epididymidis of control and flutamide-treated 25-day-old rats. The mean pixel intensity of AQP9-associated fluorescence in the apical pole of principal cells was markedly decreased following flutamide treatment. Data are expressed relative to control and represent the means \pm S.E.M. obtained from three animals per group. $* P<0.05$ versus control.

\section{Materials and Methods}

\section{Animals and treatments}

All the animal studies were performed under license from and in accordance with the legal requirements of the UK Home Office. Wistar male rats received postnatal treatments (day of birth is assigned as day 1). Irrespective of the treatment received, pups were weaned at 22 days and fed on standard rat breeding diet no. 3 (SDS, Dundee, Scotland). All animals in this study were killed on day 25, a time at which maximal AQP9 expression was reached in nontreated rats (Pastor-Soler et al. 2001, Da Silva et al. 2006b).

\section{Neonatal rats treated with androgens and/or estrogens}

The first group of animals had been treated previously with modulators of androgens and estrogens, and were characterized for the efficacy of each treatment (Fisher et al. 2002). Archival epididymis sections were used in the present study. These animals received one of the following s.c. treatments:

1) Control group $(n=6): 20 \mu \mathrm{l}$ corn oil administered on alternate days (2-12 inclusive)

2) GNRHa group $(n=6): 10 \mathrm{mg} / \mathrm{kg}$ of a long acting GNRHa (Antarelix; Europeptides, Argenteuil, France) in 5\% mannitol administered on postnatal days 2 and 5 .

3) DES group (Sigma Chemical Company) $(n=4): 10 \mu \mathrm{g}$ in $20 \mu \mathrm{l}$ corn oil administered on alternate days (2-12 inclusive).

4) Ethinyl estradiol (EE group; Sigma) $(n=8): 10 \mu$ in $20 \mu \mathrm{l}$ corn oil administered on alternate days (2-12 inclusive).

5) DES + testosterone (DES + TE group) $(n=5): 10 \mu \mathrm{g}$ DES co-administered with $200 \mu$ g testosterone esters (Sustanon, Organon Labs, Cambridge, UK) in $20 \mu \mathrm{l}$ corn oil on alternate days (2-12 inclusive).

\section{Flutamide-treated neonatal rats}

A second series of animals had also been treated and characterized previously (Fisher et al. 2002). They received s.c. injections of either:
1) Flutamide (androgen receptor antagonist, Sigma) $(n=3)$ : $50 \mathrm{mg} / \mathrm{kg}$ in $20 \mu \mathrm{l}$ of corn oil on alternate days $(2-12$ inclusive) or

2) Corn oil $(20 \mu \mathrm{l})$ administered on alternate days from day 2 to 12 inclusive (control group; $n=3$ ).

Testosterone levels measured at postnatal day 25 were significantly reduced in the GNRHa, DES, and EE groups (Fisher et al. 2002). In addition, a significant testis weight reduction ( $>85 \%$ ) was observed in the GNRHa, DES, EE, and DES + TE groups, demonstrating the effectiveness of the respective treatments in retarding testicular development (Fisher et al. 2002). In contrast, neonatal administration of flutamide was without significant effects on plasma testosterone levels and testicular weight.

\section{Tissue fixation and immunocytochemistry}

Tissue preparation

Rats were killed by inhalation of $\mathrm{CO}_{2}$ followed by cervical dislocation. The right epididymis from each animal was fixed by immersion in periodate-lysine-paraformaldehyde (PLP) containing $2 \%$ paraformaldehyde for $\sim 5 \mathrm{~h}$ at room temperature. The left epididymis was snap frozen and stored at $-80^{\circ} \mathrm{C}$

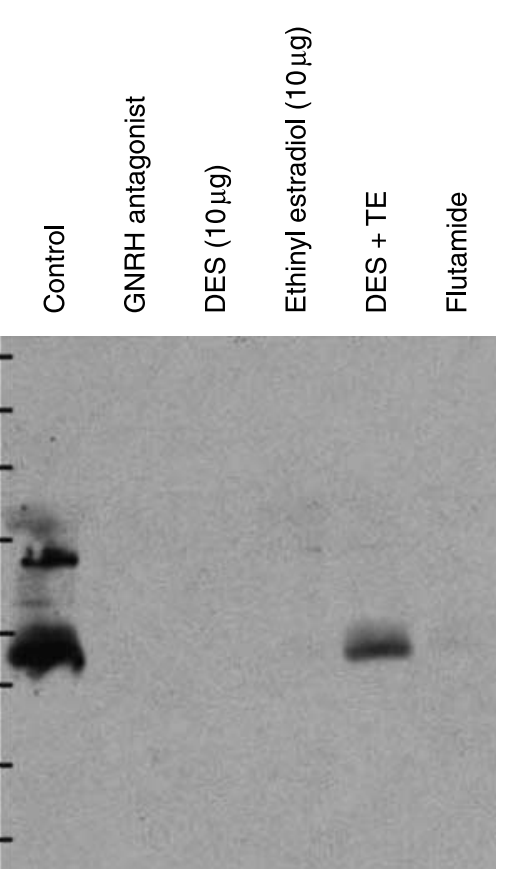

Figure 6 Western blot showing downregulation of AQP9 in epididymis of 25-day-old rats by different hormonal treatments. A strong band at $\sim 30-35 \mathrm{kDa}$ is present in total epididymal homogenate membrane of control animals. Additional, higher molecular weight bands probably represent different glycosylation states of AQP9. AQP9 was not detectable in the GNRHa-, DES- and EE-treated groups. In the DES+ TE-treated animals, a brighter AQP9 band was detected compared to DES treatment alone. A very faint AQP9 band was detected in the flutamide-treated group. Each well was loaded with the same amount of protein (Fisher et al. 2002). 
prior to protein extraction. The right testis was weighed after necropsy, and their weights are reported in our previous publication (Fisher et al. 2002).

\section{Antibodies}

An affinity-purified rabbit primary antibody against AQP9 was used for western blotting and immunofluorescence labeling. This antibody was raised against a C-terminal peptide from rat AQP9 (PSENNLEKHELSVIM-C) and has been previously characterized (Pastor-Soler et al. 2001, 2002, Da Silva et al. 2006b, Pietrement et al. 2008).

\section{Immunofluorescence labelling}

PLP-fixed tissues were cryoprotected in a solution of $30 \%$ sucrose in PBS. Tissues were embedded in OCT compound (Tissue-Tek; Sakura, Finetek USA, Torrance, CA, USA), mounted on a cutting block, and frozen in a Reichert Frigocut or a Leica 3050 cryotome (spencer Scientific). The tissue was then cut at $4 \mu \mathrm{m}$ thickness, and sections were placed onto Fisher Superfrost Plus microscope slides (Fisher Scientific, Pittsburgh, PA, USA). After rehydration in PBS at room temperature, all tissue slides were pretreated with 1\% SDS for $4 \mathrm{~min}$, as previously described (Brown et al. 1996). The slides were then washed in PBS $(3 \times 5 \mathrm{~min})$ and pre-incubated in $1 \% \mathrm{BSA}$ in $\mathrm{PBS} / 0.02 \%$ sodium azide for $15 \mathrm{~min}$ at room temperature to block nonspecific staining. The anti-AQP9 antibody was prepared at a dilution of 1:3200 in antibody diluent (DAKO, Carpinteria, CA, USA) and applied for $75 \mathrm{~min}$ at room temperature. The slides were then washed twice for 5 min in high salt PBS $(2.7 \% \mathrm{NaCl})$ to reduce nonspecific staining, and once in normal PBS. Some slides were also incubated with anti-AQP9 antibody that had been premixed with a tenfold excess of the immunizing peptide (PSENNLEKHELSVIM-C). The secondary antibody (a goat anti-rabbit IgG coupled to $\mathrm{CY} 3$ ) was applied for $1 \mathrm{~h}$ at room temperature (Jackson Immunologicals, West Grove, PA, USA), followed by three washes as described for the primary antibody. The slides were mounted in Vectashield (Vector Labs, Burlingame, CA, USA) diluted 1:1 in Tris buffer $\mathrm{pH} 8.5$ and examined using a Nikon E800 epifluorescence microscope. Digital images were obtained using a Hamamatsu Orca CCD camera and IPLab Spectrum software (Scanalytics, Vianna, VA, USA). The final images were imported into and printed from Adobe Photoshop.

\section{Quantification of AQP9 expression by immunofluorescence labeling}

Immunofluorescence labeling of each tissue was performed in at least three independent incubations, each incubation including slides from all treatment groups. All slides for a particular incubation were treated under identical conditions, and digital images were obtained using identical acquisition parameters. Each image was corrected for its own luminal unstained background value, and the MPI of apical AQP9associated fluorescence was measured using IPLab Spectrum software. The segmentation function of IPLab spectrum was used to set the minimum pixel intensity for inclusion in the quantification so that the selected pixels corresponded to the brush border membrane area of principal cells observed in the initial, non-manipulated image (see Results). We have previously used this method to quantify the downregulation of epididymal AQP9 expression induced by flutamide in adult rats (Pastor-Soler et al. 2002).

\section{Statistical analysis}

GNRHa, DES, EE, and DES+TE treatments

Overall, 28 rats were treated in the first experimental setting (control rats and rats treated with GNRHa, DES, EE, and $\mathrm{DES}+\mathrm{TE})$. In order to minimize procedural variations, 15 epididymis slides including three animals from each group were treated per incubation. Thus, the epididymis from one given rat was sampled multiple times. The MPI of AQP9associated fluorescence for each rat was normalized to the average control group value for the corresponding incubation. The purpose of this normalization procedure was to correct for any potential variations that might occur between incubations. All normalized values for each rat were averaged and analyzed. A one-way ANOVA was conducted to determine whether the treatment groups differed. A Tukey's post hoc test was then conducted to determine which group(s) was/were significantly different from one another. The mean difference was considered significant at $P=0.05$.

\section{Flutamide treatment}

In this experimental setting, statistical significance of the flutamide effect on the AQP9-associated MPI was compared to its own control group, using a one-tailed Student's $t$-test at the 0.05 level of significance.

\section{Protein extraction and immunoblotting (SDS-PAGE and western blotting)}

\section{Protein extraction}

For each treatment group, whole epididymides of 25-day-old rats were powdered in a porcelain mortar under liquid nitrogen, and the powder was stored on dry ice. Protein was extracted by the addition of $200 \mathrm{ml}$ cold extraction buffer containing $10 \mathrm{mM}$ HEPES, $\mathrm{pH}$ 7.9; $0.1 \mathrm{mM}$ EGTA; $1 \mathrm{mM}$ dithiothreitol; $0.5 \mathrm{mM}$ phenylmethylsulphonyl fluoride; and Complete protease inhibitors (Roche). The tissue was left on ice for $15 \mathrm{~min}$ prior to the addition of $25 \mathrm{ml}$ of $10 \%$ Nonidet P-40 (Sigma) to the tube, which was then vortexed thrice for $10 \mathrm{~s}$ each. After centrifugation at $12000 \mathrm{~g}$ for $1 \mathrm{~min}$ at $4{ }^{\circ} \mathrm{C}$, the supernatant was decanted, and $100 \mathrm{mg}$ aliquots were frozen on dry ice before being stored at $-40{ }^{\circ} \mathrm{C}$.

\section{Western blot analysis}

Protein samples (from all treatment groups) and protein markers (Bio-Rad) were separated by SDS-PAGE using 4-20\% gradient gels (Invitrogen). The gels were run at $110 \mathrm{~V}$ for $\sim 2 \mathrm{~h}$ before blotting onto a PVDA membrane (Immobilon-P) at $33 \mathrm{~V}$ for $180 \mathrm{~min}$ in Tris/glycine transfer buffer (Invitrogen). 
Membranes were blocked with 5\% milk in TBS for $1 \mathrm{~h}$ at room temperature, and then washed in TBST (Tris-buffered saline; $50 \mathrm{mM}$ Tris- $\mathrm{HCl}, 150 \mathrm{mM} \mathrm{NaCl}$ containing 0.05\% Tween-20; Sigma). The membranes were incubated with the AQP9 antibody, diluted $1: 2000$ in TBS $/ 0.02 \%$ sodium azide at $4{ }^{\circ} \mathrm{C}$ overnight. After extensive washes in TBST, a goat anti-rabbit IgG conjugated to HRP (Sigma) was applied to membranes at a dilution of 1:10 000. After washing, AQP9 was detected using the ECL kit (Amersham), and membranes were exposed to film (Kodak) until optimal development of the signal was detected.

\section{Declaration of interest}

The authors declare that there is no conflict of interest that could be perceived as prejudicing the impartiality of the research reported.

\section{Funding}

This work was supported by NIH grants HD45821 (S Breton), DK38452 (D Brown and S Breton). N M Pastor-Soler was supported by an NIH NRSA award HD08684. J S Fisher was supported by contract QLK4-1999-01422 from the European Union.

\section{Acknowledgements}

We would like to thank Dr Kimberly Cavoto for her help with statistical analysis of the data.

\section{References}

Atanassova N, McKinnell C, Walker M, Turner KJ, Fisher JS, Morley M, Millar MR, Groome NP \& Sharpe RM 1999 Permanent effects of neonatal estrogen exposure in rats on reproductive hormone levels, Sertoli cell number, and the efficiency of spermatogenesis in adulthood. Endocrinology 140 5364-5373.

Atanassova N, McKinnell C, Fisher J \& Sharpe RM 2005 Neonatal treatment of rats with diethylstilboestrol (DES) induces stromal-epithelial abnormalities of the vas deferens and cauda epididymis in adulthood following delayed basal cell development. Reproduction 129 589-601.

Badran HH \& Hermo LS 2002 Expression and regulation of aquaporins 1, 8, and 9 in the testis, efferent ducts, and epididymis of adult rats and during postnatal development. Journal of Andrology 23 358-373.

Bagnis C, Marsolais M, Biemesderfer D, Laprade R \& Breton S 2001 $\mathrm{Na}^{+} / \mathrm{H}^{+}$-exchange activity and immunolocalization of NHE3 in rat epididymis. American Journal of Physiology. Renal Physiology $\mathbf{2 8 0}$ F426-F436.

Belleannee C, Da Silva N, Shum WW, Marsolais M, Laprade R, Brown D \& Breton S 2009 Segmental expression of the bradykinin type 2 receptor in rat efferent ducts and epididymis and its role in the regulation of aquaporin 9. Biology of Reproduction 80 134-143.

Breton S, Tyszkowski R, Sabolic I \& Brown D 1999 Postnatal development of $\mathrm{H}^{+}$ATPase (proton-pump)-rich cells in rat epididymis. Histochemistry and Cell Biology 111 97-105.

Brown D, Verbavatz JM, Valenti G, Lui B \& Sabolic I 1993 Localization of the CHIP28 water channel in reabsorptive segments of the rat male reproductive tract. European Journal of Cell Biology 61 264-273.

Brown D, Katsura T, Kawashima M, Verkman AS \& Sabolic I 1995 Cellular distribution of the aquaporins: a family of water channel proteins. Histochemistry and Cell Biology 104 1-9.
Brown D, Lydon J, McLaughlin M, Stuart-Tilley A, Tyszkowski R \& Alper S 1996 Antigen retrieval in cryostat tissue sections and cultured cells by treatment with sodium dodecyl sulfate (SDS). Histochemistry and Cell Biology 105 261-267.

Cheung KH, Leung GP, Leung MC, Shum WW, Zhou WL \& Wong PY 2005 Cell-cell interaction underlies formation of fluid in the male reproductive tract of the rat. Journal of General Physiology 125 443-454.

Clulow J, Jones RC, Hansen LA \& Man SY 1998 Fluid and electrolyte reabsorption in the ductuli efferentes testis. Journal of Reproduction and Fertility Supplement 53 1-14.

Cooper TG \& Brooks DE 1981 Entry of glycerol into the rat epididymis and its utilization by epididymal spermatozoa. Journal of Reproduction and Fertility 61 163-169.

Da Silva N, Pietrement C, Brown D \& Breton S 2006a Segmental and cellular expression of aquaporins in the male excurrent duct. Biochimica et Biophysica Acta 1758 1025-1033.

Da Silva N, Silberstein C, Beaulieu V, Pietrement C, Van Hoek AN, Brown D \& Breton S 2006b Postnatal expression of aquaporins in epithelial cells of the rat epididymis. Biology of Reproduction $\mathbf{7 4}$ 427-438.

Elkjaer M, Vajda Z, Nejsum LN, Kwon T, Jensen UB, Amiry-Moghaddam M, Frokiaer J \& Nielsen S 2000 Immunolocalization of AQP9 in liver, epididymis, testis, spleen, and brain. Biochemical and Biophysical Research Communications 276 1118-1128.

Fisher JS, Turner KJ, Fraser HM, Saunders PT, Brown D \& Sharpe RM 1998 Immunoexpression of aquaporin-1 in the efferent ducts of the rat and marmoset monkey during development, its modulation by estrogens, and its possible role in fluid resorption. Endocrinology 139 3935-3945.

Fisher JS, Pastor-Soler N, Sharpe RM \& Breton S 2002 Modulation of the onset of postnatal development of $\mathrm{H}(+)$-ATPase-rich cells by steroid hormones in rat epididymis. Biology of Reproduction 67 1106-1114.

Goyal HO, Robateau A, Braden TD, Williams CS, Srivastava KK \& Ali K 2003 Neonatal estrogen exposure of male rats alters reproductive functions at adulthood. Biology of Reproduction 68 2081-2091.

Hansen LA, Dacheux F, Man SY, Clulow J \& Jones RC 2004 Fluid reabsorption by the ductuli efferentes testis of the rat is dependent on both sodium and chlorine. Biology of Reproduction 71 410-416.

Hermo L, Schellenberg M, Liu LY, Dayanandan B, Zhang T, Mandato CA \& Smith CE 2008 Membrane domain specificity in the spatial distribution of aquaporins 5, 7, 9, and 11 in efferent ducts and epididymis of rats. Journal of Histochemistry and Cytochemistry 56 1121-1135.

Hess RA 2003 Estrogen in the adult male reproductive tract: a review. Reproductive Biology and Endocrinology 152.

Hess RA, Bunick D, Lee KH, Bahr J, Taylor JA, Korach KS \& Lubahn DB 1997 A role for oestrogens in the male reproductive system. Nature 390 509-512.

Hinton BT \& Palladino MA 1995 Epididymal epithelium: its contribution to the formation of a luminal fluid microenvironment. Microscopic Research and Technique 30 67-81.

Hohlbrugger G \& Pfaller K 1983 Post-vasectomy impairment of transepithelial water reabsorption in the initial segment of the epididymis. Archives of Andrology 11 265-270.

Ilio KY \& Hess RA 1994 Structure and function of the ductuli efferentes: a review. Microscopic Research and Technique 29 432-467.

Johnson AL \& Howards SS 1977 Hyperosmolality in intraluminal fluids from hamster testis and epididymis: a micropuncture study. Science 195 492-493.

Joseph A, Yao H \& Hinton BT 2009 Development and morphogenesis of the Wolffian/epididymal duct, more twists and turns. Developmental Biology 325 6-14.

Kaunisto KM \& Rajaniemi HJ 2002 Expression and localization of the $\mathrm{Na}^{+} / \mathrm{H}^{+}$exchanger isoform NHE3 in the rat efferent ducts. Journal of Andrology 23 237-241.

King LS, Kozono D \& Agre P 2004 From structure to disease: the evolving tale of aquaporin biology. Nature Reviews. Molecular Cell Biology $\mathbf{5}$ 687-698.

Leung GP, Tse CM, Chew SB \& Wong PY 2001 Expression of multiple $\mathrm{Na}^{+} / \mathrm{H}^{+}$exchanger isoforms in cultured epithelial cells from rat efferent duct and cauda epididymidis. Biology of Reproduction 64 482-490. 
Levine N \& Marsh DJ 1971 Micropuncture studies of the electrochemical aspects of fluid and electrolyte transport in individual seminiferous tubules, the epididymis and the vas deferens in rats. Journal of Physiology 213 557-570.

McKinnell C, Atanassova N, Williams K, Fisher JS, Walker M, Turner KJ, Saunders TK \& Sharpe RM 2001 Suppression of androgen action and the induction of gross abnormalities of the reproductive tract in male rats treated neonatally with diethylstilbestrol. Journal of Andrology 22 323-338.

Nicchia GP, Frigeri A, Nico B, Ribatti D \& Svelto M 2001 Tissue distribution and membrane localization of aquaporin-9 water channel: evidence for sex-linked differences in liver. Journal of Histochemistry and Cytochemistry 49 1547-1556.

Oliveira CA, Carnes K, Franca LR, Hermo L \& Hess RA 2005 Aquaporin-1 and -9 are differentially regulated by oestrogen in the efferent ductule epithelium and initial segment of the epididymis. Biology of the Cell 97 385-395.

Pastor-Soler N, Bagnis C, Sabolic I, Tyszkowski R, McKee M, Van Hoek A, Breton S \& Brown D 2001 Aquaporin 9 expression along the male reproductive tract. Biology of Reproduction 65 384-393.

Pastor-Soler N, Isnard-Bagnis C, Herak-Kramberger C, Sabolic I, Van Hoek A, Brown D \& Breton S 2002 Expression of aquaporin 9 in the adult rat epididymal epithelium is modulated by androgens. Biology of Reproduction 66 1716-1722.

Picciarelli-Lima P, Oliveira AG, Reis AM, Kalapothakis E, Mahecha GA, Hess RA \& Oliveira CA 2006 Effects of 3-beta-diol, an androgen metabolite with intrinsic estrogen-like effects, in modulating the aquaporin-9 expression in the rat efferent ductules. Reproductive Biology and Endocrinology 451.

Pietrement C, Da Silva N, Silberstein C, James $M$, Marsolais $M$, Van Hoek A, Brown D, Pastor-Soler N, Ameen N, Laprade R et al. 2008 Role of NHERF1, cystic fibrosis transmembrane conductance regulator, and CAMP in the regulation of aquaporin 9. Journal of Biological Chemistry 283 2986-2996.

Rivas A, Fisher JS, McKinnell C, Atanassova N \& Sharpe RM 2002 Induction of reproductive tract developmental abnormalities in the male rat by lowering androgen production or action in combination with a low dose of diethylstilbestrol: evidence for importance of the androgen-estrogen balance. Endocrinology 143 4797-4808.

Rivas A, McKinnell C, Fisher JS, Atanassova N, Williams K \& Sharpe RM 2003 Neonatal coadministration of testosterone with diethylstilbestrol prevents diethylstilbestrol induction of most reproductive tract abnormalities in male rats. Journal of Andrology 24 557-567.

Robaire B \& Viger RS 1995 Regulation of epididymal epithelial cell functions. Biology of Reproduction 52 226-236.

Robaire B, Hinton BT \& Orgebin-Crist M-C 2006 The epididymis. In Physiology of Reproduction, 3 edn, pp 1071-1148. Ed. JD Neill. New York: Elsevier.
Ruz R, Gregory M, Smith CE, Cyr DG, Lubahn DB, Hess RA \& Hermo L 2006 Expression of aquaporins in the efferent ductules, sperm counts, and sperm motility in estrogen receptor-alpha deficient mice fed lab chow versus casein. Molecular Reproduction and Development 73 226-237.

Shum WW, Da Silva N, McKee M, Smith PJ, Brown D \& Breton S 2008 Transepithelial projections from basal cells are luminal sensors in pseudostratified epithelia. Cell 135 1108-1117.

Stevens AL, Breton S, Gustafson CE, Bouley R, Nelson RD, Kohan DE \& Brown D 2000 Aquaporin 2 is a vasopressin-independent, constitutive apical membrane protein in rat vas deferens. American Journal of Physiology. Cell Physiology 278 C791-C802.

Tsukaguchi H, Shayakul C, Berger UV, Mackenzie B, Devidas S, Guggino WB, van Hoek AN \& Hediger MA 1998 Molecular characterization of a broad selectivity neutral solute channel. Journal of Biological Chemistry 273 24737-24743.

Turner TT 1995 On the epididymis and its role in the development of the fertile ejaculate. Journal of Andrology 16 292-298.

Turner TT \& Cesarini DM 1983 The ability of the rat epididymis to concentrate spermatozoa. Responsiveness to aldosterone. Journal of Andrology 4 197-202.

Verkman AS 2002 Physiological importance of aquaporin water channels. Annals of Medicine 34 192-200.

Wellejus A, Jensen HE, Loft S \& Jonassen TE 2008 Expression of aquaporin 9 in rat liver and efferent ducts of the male reproductive system after neonatal diethylstilbestrol exposure. Journal of Histochemistry and Cytochemistry $\mathbf{5 6}$ 425-432.

Williams K, McKinnell C, Saunders PT, Walker M, Fisher JS, Turner KJ, Atanassova N \& Sharpe M 2001 Neonatal exposure to potent and environmental oestrogens and abnormalities of the male reproductive system in the rat: evidence for importance of the androgen-oestrogen balance and assessment of the relevance to man. Human Reproduction Update 7 236-247.

Wong PY 1998 CFTR gene and male fertility. Molecular Human Reproduction 4 107-110.

Wong PY \& Yeung CH 1977 Fluid reabsorption in the isolated duct of the rat cauda epididymidis. Journal of Reproduction and Fertility 49 77-81.

Wong PY \& Yeung CH 1978 Absorptive and secretory functions of the perfused rat cauda epididymidis. Journal of Physiology 275 13-26.

Zhou Q, Nie R, Prins GS, Saunders PT, Katzenellenbogen BS \& Hess RA 2002 Localization of androgen and estrogen receptors in adult male mouse reproductive tract. Journal of Andrology 23 870-881.

Received 7 July 2009

First decision 4 September 2009

Revised manuscript received 6 November 2009

Accepted 30 November 2009 